Bangladesh J. Plant Taxon. 28(1): 17-26, 2021 (June)

(C) 2021 Bangladesh Association of Plant Taxonomists

https://doi.org/10.3329/bjpt.v28i1.54206

\title{
RUBROBOLETUS HIMALAYENSIS SARWAR \& KHALID - A NEW MUSHROOM FROM PAKISTAN
}

\author{
Samina Sarwar*, Zeb Siddique, Ayesha Bashir and Abdul Nasir Khalid ${ }^{1}$ \\ Department of Botany, Lahore College for Women University, Lahore, Pakistan
}

Keywords: Ectomycorrhizae; Himalayan range; ITS region; Macrofungi; Molecular phylogeny.

\begin{abstract}
Rubroboletus himalayensis sp. nov. (Boletaceae, Boletales, Basidiomycota) was collected from diversity rich Himalayan range of Pakistan and characterised by combination of morphological and molecular methods. Its mycochemical screening as well as antioxidant analysis was also done. Comparison with closely related species was also done. The nuclear ribosomal internal transcribed spacer (ITS) region was sequenced and then the phylogenetic analysis was performed for the focal fungus and its related species. Mycochemical analysis of this mushroom indicated the presence of proteins, triterpenoids, flavonoids, tannins and phenolics while absence of alkaloids, carbohydrates, steroids, saponins, anthocyanins. Quantitative analysis of mycochemicals revealed that the total phenolic and tannin contents were highest in methanol extracts (7.66 mg GAE/g dW and $441.0 \mathrm{mg} \mathrm{TAE} / \mathrm{g} \mathrm{dW}$, respectively) while the flavonoid contents were highest in n-hexane extract $(607.0 \mathrm{mg} \mathrm{QE} / \mathrm{g} \mathrm{dW})$. All the extracts were subjected to DPPH radical scavenging assay. Maximum antioxidant activity at $1 \mathrm{mg} / \mathrm{ml}$ was observed in dichloromethane extract of $R$. himalayensis that is $98.14 \%$. At $0.125 \mathrm{mg}$ $/ \mathrm{mL}$ concentration, the highest antioxidant activity was observed for dichloromethane extract $(34.43 \%)$ and lowest in ethyl acetate (19.66\%). The present study results showed that the analysed mushroom is new to science and has medicinal power due to the presence of various mycochemicals and its antioxidant potential.
\end{abstract}

\section{Introduction}

Mushrooms including boletes have been used as food as well as acknowledged for their excellent taste, commercial and environmental values, and pharmaceutical properties for many years (Sanchez, 2010; Vamanu and Nita, 2013). They elevate health due to the presence of bioactive compounds (Wang et al., 2014; Pascua et al., 2016) which can provide curative or nutritious aid to humans. Their chemical composition is mainly responsible for the therapeutic properties (Bernas et al., 2006). Boletes have been demonstrated many pharmacological effects like antitumor, antifungal, antibacterial activities, antioxidant, immuno-modulatory, antiallergic, antiatherogenic, hypoglycemic and haematological properties, along with hormones, pheromones, toxins, carcinogenic enzymes, antibiotics, anticarcinogens and pigment genetically (Lucas et al., 1957; Palacios et al., 2011) which are useful in preventing many diseases (Ribeiro et al., 2006).

Boletes are an economically important group of Basidiomycetous; characterized by having pores instead of gills as their fertile part. They are mostly found in symbiotic association with roots of higher plants. Many members in this group are found as edible and of medicinal importance (Luo et al., 2012; Vamanu and Nita, 2013), but there is scarce literature with relevant to Pakistan species as well as regarding mycochemical analysis of these fungi (Sarwar, 2013).

*Corresponding author. E-mail: samina_boletus@yahoo.com

${ }^{1}$ Department of Botany, University of the Punjab, Lahore, 54590, Pakistan. 
Boletes should be promoted as an effective food supplements for health maintenance (Lemieszek et al., 2016) as it is diverse in its mycochemical components (Wang et al., 2014) and advantages are from this investigation with respect to medicinal finding.

The present study highlights the finding of a new mushroom belonging to Rubroboletus genus from northern areas of Pakistan as well as its mycochemical analysis in an effort to contribute the documentation and to put light on the importance of hidden diversity. Members of Rubroboletus have a grayish red to vivid red or dark red pileus, yellow tubes, an orange red to blood red surface of the hymenophore, dark red to brown reticula (obvious or coarse) on the stipe and a non-amyloid context (Singer and Kuthan, 1976; Alessio, 1985; Estadès and Lannoy, 2004; Muñoz, 2005). Mostly members of this genus phylogenetically analysed by ITS (some unpublished and some published) region but few members were also analysed by other gene markers i.e., nrLSU, tef1- $\alpha$, rpb1 and rpb2 (Zhao et al., 2014).

\section{Materials and Methods}

Sampling and morphological analysis

Basidioma were collected during the rainy season (June-August, 2009-2011) from Himalayan Moist Temperate forests of Pakistan dominated by coniferous trees. Macromorphological characteristics were recorded in the field. Microscopical characteristics were studied in the laboratory based on dried specimens and were deposited in Lahore Herbarium, Department of Botany, University of the Punjab, Lahore, Pakistan (LAH). For light microscopy (LM), samples were rehydrated using $5 \% \mathrm{KOH}$. Tissues from hymenophore, pileipellis and stipitipellis were mounted in $1 \%$ Phloxine for better contrast. Melzer's reagent was used to test for amyloid reactions in basidiospores and measurements of about 50 spores per specimen were determined with ScopeImage 9 (5.0) software HDCE-x5. Spore measurements are presented as the ranges of length and width and extreme values are given in parentheses. The range contains a minimum of $90 \%$ of the values. $Q$ indicates $1 / \mathrm{w}$ ratio of individual spore and $\mathrm{Q}_{\mathrm{m}}$ means average $\mathrm{Q}$ of all spores \pm standard deviation. Basidiospores were also analysed through scanning electron microscope (SEM).

\section{Molecular and phylogenetic analysis}

DNA was extracted from dried sporocarps following a modified CTAB method (Gardes and Bruns, 1996). Primer pairs ITS1F/ITS4 (White et al., 1990) for the ITS region of nuclear ribosomal DNA was used for PCR and Sanger sequencing. All PCR products were evaluated for successful amplification using SYBR Green and 1.5\% agarose gels with TAE buffer for gel electrophoresis. Amplicons were prepared for sequencing via enzymatic purification using Exonuclease I and Shrimp Alkaline Phosphatase enzymes (Werle et al., 1994). Purified products were sequenced from Macrogen Korea.

Sequencing chromatograms were edited by comparing overlapping reads using BioEdit and compared to GenBank records using BLAST. From GenBank, ITS sequences of closely related taxa were retrieved for phylogenetic analysis. The sequence alignment was carried out using MUSCLE alignment software (Edgar, 2004). Phylogenetic analysis was done with the maximum likelihood algorithm and Jukes and Cantor (1969) model of sequences evolution using Model testing feature of MEGA5 software (Tamura et al., 2011). In the final analysis 28 sequences were used for constructing phylogenetic tree. To avoid taxonomic confusion, the name for the newly described species has been listed with respective GenBank accession numbers in the phylogenetic tree (Fig. 2). Bootstrap consensus tree was inferred from 1000 replicates, and corresponding bootstrap values $>50 \%$ are cited in the tree. 


\section{Mycochemicals extraction and screening}

Extraction of samples was done in Soxhlet sequentially using solvents of ascending polarity from nonpolar to polar that ensured the extraction of wide polarity range of compounds. The nhexane, dichloromethane, ethyl acetate, acetone and methanol extracts were subjected to standard mycochemical analysis to ensure the presence of different myconstituents (Parihar et al., 2015) through specific established tests for each mycochemical including alkaloid, carbohydrates, glycosides, proteins and amino acids, flavonoids, triterpenoids, steroids, phenolics, tannins, saponins, quinones and betacyanins (Harborne, 1973). Quantitative analysis of mycochemicals present in basidioma was done by following standard methods for different chemicals (Ram and Mehrotra, 1993).

\section{Determination of antioxidant activity}

For estimation of antioxidant activity, $200 \mu \mathrm{L}$ of sample extracts (at various concentrations $0.125,0.25,0.5$ and $1 \mathrm{mg} / \mathrm{mL}$ ) was mixed with $2 \mathrm{~mL}$ of $0.05 \mathrm{mM}$ methanol solution of DPPH and incubated for 30 minutes at room temperature. Absorbance of all the reaction mixtures and control (ascorbic acid) was measured at $517 \mathrm{~nm}$ in UV-VIS spectrophotometer with methanol as blank. The control contained all the reagents except the sample extract. The \% inhibition of DPPH radical (1\%) was calculated by following formula described by Hatano et al. (1988).

Inhibition $(\%)=100 \times\left(\mathrm{A}_{0}-\mathrm{As}\right) / \mathrm{A}_{\mathrm{o}}$

Where, $A_{o}=$ absorbance of the control, $A s=$ absorbance of the tested sample. The $\mathrm{IC}_{50}$ value $(\mathrm{mg} / \mathrm{mL})$ of each sample was also calculated by linear regression analysis.

\section{Results and Discussion}

\section{Taxonomy}

Rubroboletus himalayensis Sarwar \& Khalid sp. nov.

(Fig. 1)

MycoBank no.: MB 831169

GenBank no.: MK391936, MK391937

Etymology: himalayensis refers to locality (Himalayan range of Pakistan) from where samples were collected.

Holotype: PAKISTAN, Murree, Changla gali, $2559 \mathrm{~m}$ a.s.l., on ground, under Abies pindrow Royle, 19 Jul 2009, Sarwar S.B. \# 05 (LAH0709) (Holotype).

Morphological analysis: Pileus $15-21 \mathrm{~cm}$ in diameter, hemispherical to broadly convex to plane, surface smooth, slightly viscid when wet, shiny, reddish orange to bright red, margin straight or flaring, off-white to whitish, smooth, entire. Context light yellowish to creamish to creamish red, slowly turns blue upon exposure. Stipe 10-16 cm long, $3-6.5 \mathrm{~cm}$ wide, club shaped, bulbous at base, centric, straight to curved to irregular, yellow toward apex, brownish yellow toward base with orangish red to red fine flecks and scales toward apex, solid, context fibrous, yellow which turns readily blue upon exposure. Pore surface yellowish red toward pileus margin, reddish toward stipe, readily bluing upon bruising, pores angular to rounded, 2-3 per mm, tubes yellowish, adnate to adnexed, $8-13 \mathrm{~mm}$ deep. Basidiospores ellipsoid to fusiform, thick walled, smooth, oil drops visible, $11-13 \times 3-4 \mu \mathrm{m},\left(12 \pm 0.7 \times 3.4 \pm 0.3 ; Q_{m}=1.9 \pm 0.3\right)$. Basidia thin walled, clavate, 1-4 sterigmate, in Meltzer reagent yellowish brown contents, light yellow to hyaline in $\mathrm{KOH}, 25-31 \times 9-11 \mu \mathrm{m}$. Cystidia cylindrical to slightly clavate, light yellow in Meltzer reagent and $\mathrm{KOH}, 34-36 \times 7-8 \mu \mathrm{m}$. Pileipellis long cylindrical cells, thin walled, no contents visible, 125-127× 16-18 $\mu \mathrm{m}$, most terminal elements cylindrical, thin walled, 103-108 $(-117) \times$ $18-19 \mu \mathrm{m}$. Chemical reactions pileipellis hyaline to light yellow in $\mathrm{KOH}$; spores dark brown in Meltzer reagent, yellowish brown in $\mathrm{KOH}$. 

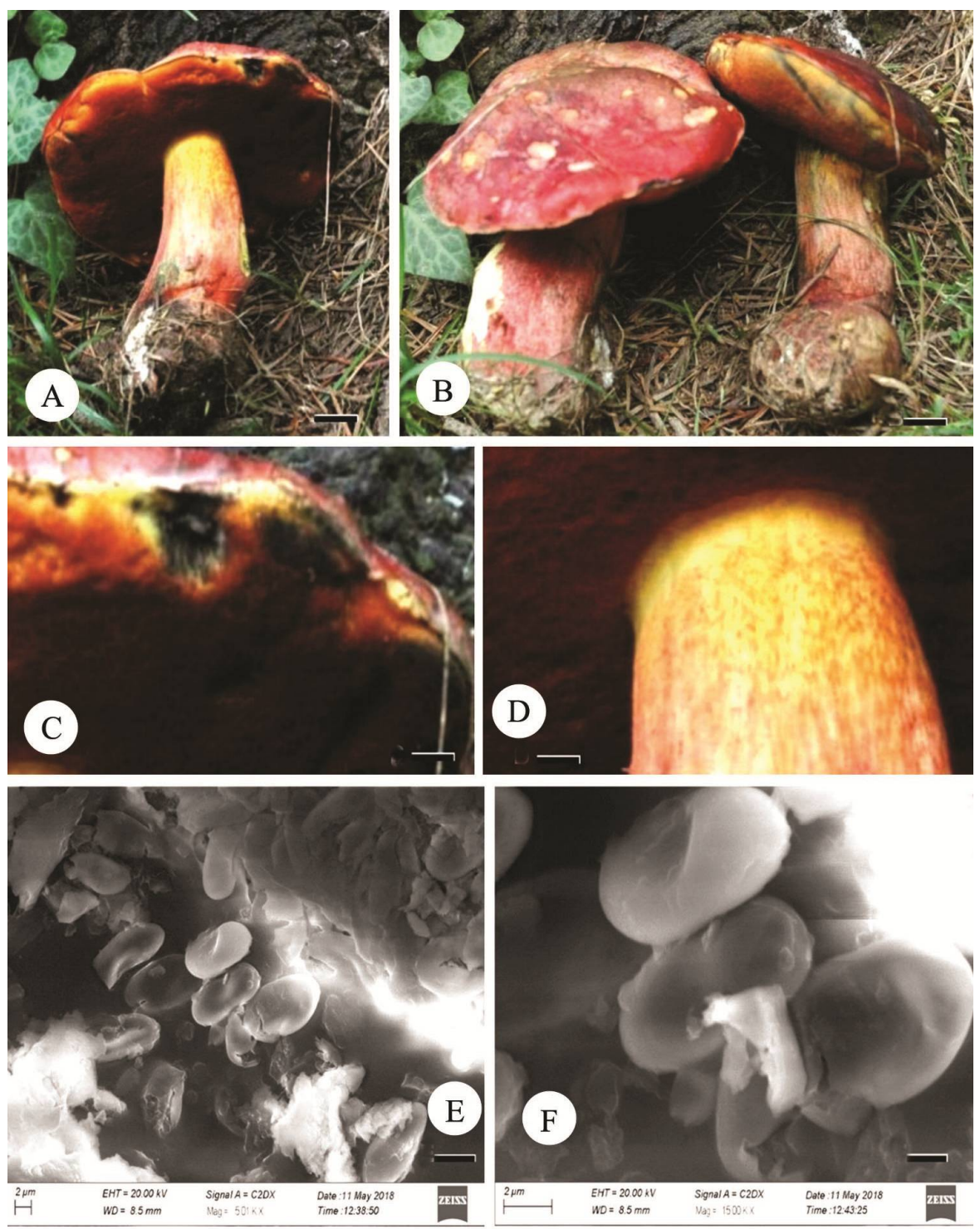

Fig. 1. Rubroboletus himalayensis (holotype): A-B. Sporocarp, C. Hymenium, D. Stipe reticula, E-F. SEM analysis of Basidiospores showing spore features. Bars $1 \mathrm{~cm}$.

Additional Material examined: PAKISTAN, Khyber Pakhtunkhwa, Khaira gali, 2347 m a.s.l., solitary, on ground, under Pinus wallichiana A.B. Jack,19Aug 2009, Sarwar S.B. \# 05A (LAH0809); PAKISTAN, Sharan (Kaghan valley), 2011 m a.s.l., 18 Jun 2011, Tayiba A. \# 42(LAH0611).

Molecular phylogeny

(Fig. 2)

R. himalayensis ITS sequences when compared with GenBank sequences through BLAST analysis, it showed maximum similarity (85\%) with $R$. lupinus (KR782309) and 83\% with $R$. 
dupainii (KR782304). For phylogenetic analysis, 798 genetic characters were used in aligned datasheet containing 474 conserved sites, 294 variable and 183 were parsimony-informative sites. In the ITS phylogram, the sequences from basidiomata of $R$. hymalayensis (MK391936 and MK391937) generated during this study form sister clade with $R$. lupinus and $R$. dupainii.

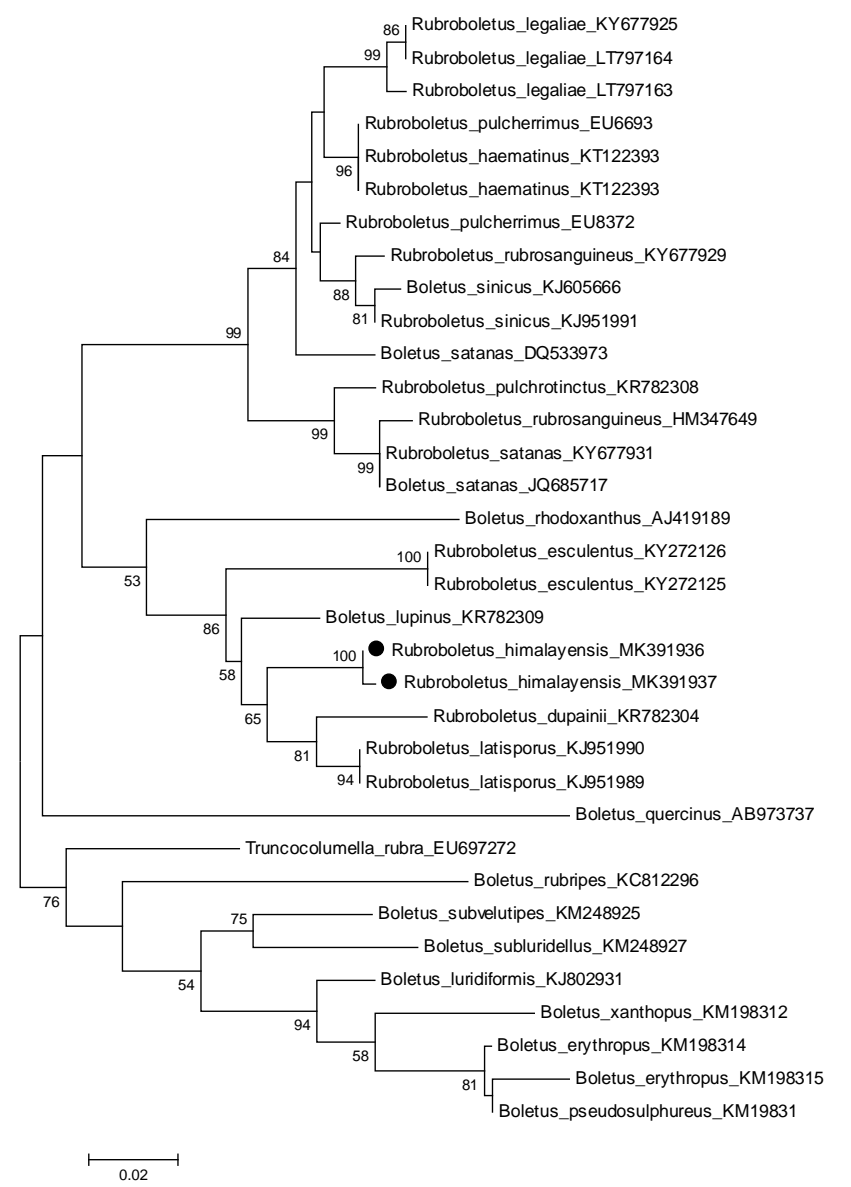

Fig. 2. Phylogenetic position of Rubroboletus himalayensis with respect to closely related species. Tree inferred by maximum likelihood analysis based on rDNA sequences, including ITS region. The numbers against branches indicate the percentage $(>50 \%)$ at which a given branch was supported in 1000 bootstrap replications. GenBank accession number are given at the end of species names. • indicate species reported from Pakistan

\section{Extraction yield}

(Figs 3-7)

Extraction yield of extracts obtained in n-hexane, dichloromethane, ethyl acetate, acetone and methanol was calculated for each sample. The results indicated highest yield in methanol $(3.7 \mathrm{~g}$ $32.45 \%)$ and lowest in ethyl acetate and acetone ( $1 \mathrm{~g}$ each-8.77 \%) in $R$. himalayensis. Mycochemical analysis

Extracts of selected mushrooms were screened for mycochemical analyses. Qualitative analysis of n-hexane, dichloromethane, ethyl acetate, acetone and methanol extracts revealed the presence of several mycochemicals viz. proteins (in dichloromethane and methanol extracts), triterpenoids (in all extracts), tannins (in all extracts), flavonoids (in all extracts), phenolics (in all extracts) and quinones (in n-hexane extract) were present. 
Quantitatively, the total phenolic content on mg per gram dry weight basis was found to be highest in methanol extract $(7.66 \mathrm{mg} \mathrm{GAE} / \mathrm{g} \mathrm{dW})$ and lowest in acetone extract $(1.86 \mathrm{mg} \mathrm{GAE} / \mathrm{g}$ $\mathrm{dW})$; flavonoid content was found to be highest in n-hexane extract (607.0 mg QE/g dW) and lowest in methanol extract $(72.5 \mathrm{mg} \mathrm{QE} / \mathrm{g} \mathrm{dW})$ and tannin content was found to be highest in methanol extract (441.0 mg TAE/g dW) and lowest in acetone extract (59.8 mg TAE/g dW).

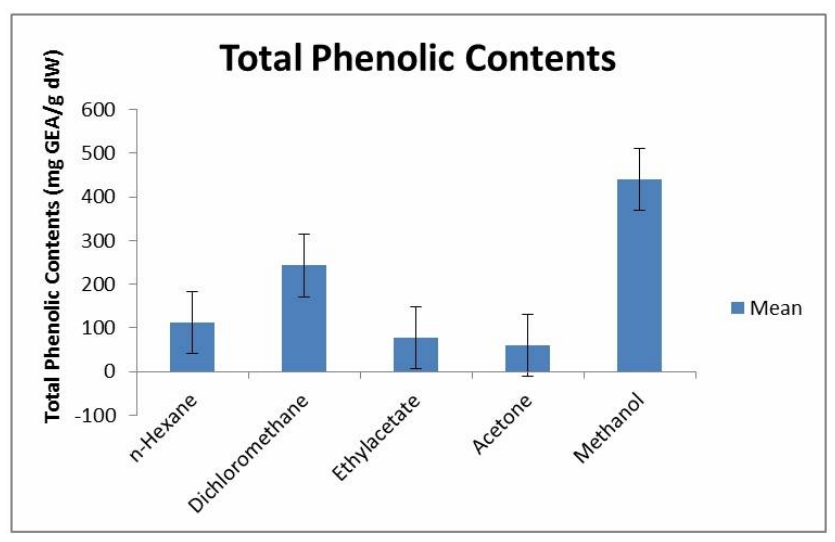

Fig. 3. Total phenolic contents in different solvent extracts of Rubroboletus himalayensis.

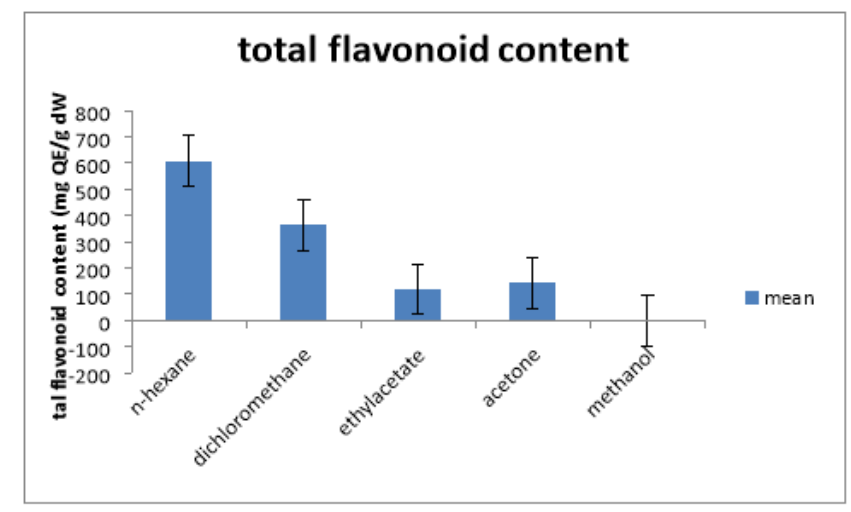

Fig. 4. Total flavonoid contents in different solvent extracts of Rubroboletus himalayensis.

\section{DPPH radical scavenging assay}

$n$-Hexane, dichloromethane, ethyl acetate, acetone and methanol extracts of $R$. himalayensis were subjected to antioxidant assay at concentrations of $0.125,0.25,0.5$ and $1 \mathrm{mg} / \mathrm{ml}$ and the results of $\%$ age inhibition were compared with standard ascorbic acid at the same concentrations. The radical scavenging activity against DPPH at all the tested concentrations with $\%$ age inhibition was ranging between 19-98\%. The results showed the dose dependent activity i.e., DPPH radical scavenging activity of different solvent extracts of all samples increased with increase in concentration of extract. All the solvent extracts exhibited antioxidant activity of varying intensity indicating that the antioxidants in it are broad spectrum in nature ranging from non-polar to polar. 
The $\mathrm{IC}_{50}$ value $(\mathrm{mg} / \mathrm{ml})$ of each sample was calculated. It is the concentration of extract which inhibits or scavenges $50 \%$ of DPPH free radicals. The relation between $\mathrm{IC}_{50}$ value and the efficiency of analysed mushroom is inverse, i.e., the lower the $\mathrm{IC}_{50}$ value the higher is the antioxidant potential. The highest \%age of antioxidant activity of $R$. himalayensis was observed in dichloromethane fraction $(98.14 \%$ ) at $1 \mathrm{mg} / \mathrm{ml}$. At $0.125 \mathrm{mg} / \mathrm{mL}$ the highest antioxidant activity was observed for the dichloromethane fraction (34.43\%) followed by $n$-hexane fraction (25.60\%), methanol fraction (25.40\%), acetone fraction (23.05\%) and ethyl acetate (19.66\%). All the extracts showed high radical scavenging activity than quercetin. The $\mathrm{IC}_{50}$ values for different extracts in descending order are; ethyl acetate $(1.246 \mathrm{mg} / \mathrm{ml})$ methanol $>(1.172 \mathrm{mg} / \mathrm{ml})>$ acetone $(0.905$ $\mathrm{mg} / \mathrm{ml})>\mathrm{n}$-hexane $(0.768 \mathrm{mg} / \mathrm{ml})>$ dichloromethane $(0.436 \mathrm{mg} / \mathrm{ml})$. The lowest $\mathrm{IC}_{50}$ value of dichloromethane $(0.436 \mathrm{mg} / \mathrm{mL})$ shows that the mycochemicals in this fraction are most active in scavenging radicals at low concentrations and show strongest antioxidant activity.

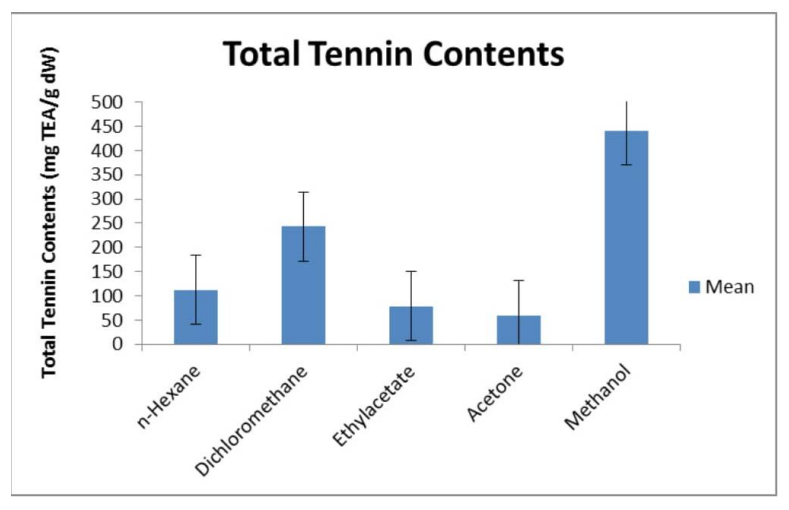

Fig. 5. Total tannin contents in different solvent extracts of Rubroboletus himalayensis.

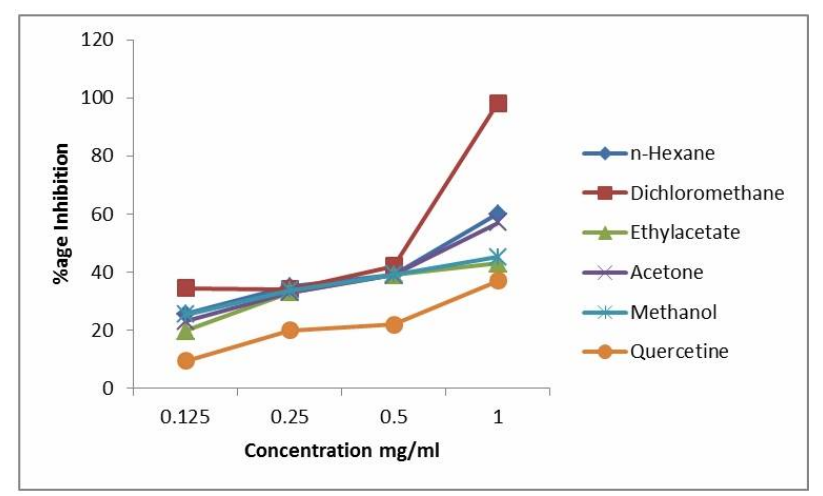

Fig. 6. DPPH radical scavenging activity of different solvent extracts of Rubroboletus himalayensis.

\section{Statistical analysis}

The statistical analysis (T-test) revealed all the extracts of $R$. himalayensis showed nonsignificant $(\mathrm{P} \geq 0.05)$ difference in antioxidant activity. However, the antioxidant activity of dichloromethane fraction was significantly higher than that of quercetin $(\mathrm{p}<0.05)$. 
This research work presented a new taxa (Rubroboletus himalayensis) belonging to Boletaceae collected from the Himalayan Moist Temperate forests of Pakistan. Although there is great diversity of this group in Pakistan but only few taxa have been reported by corresponding author (Naseer et al., 2019; Sarwar, 2013).

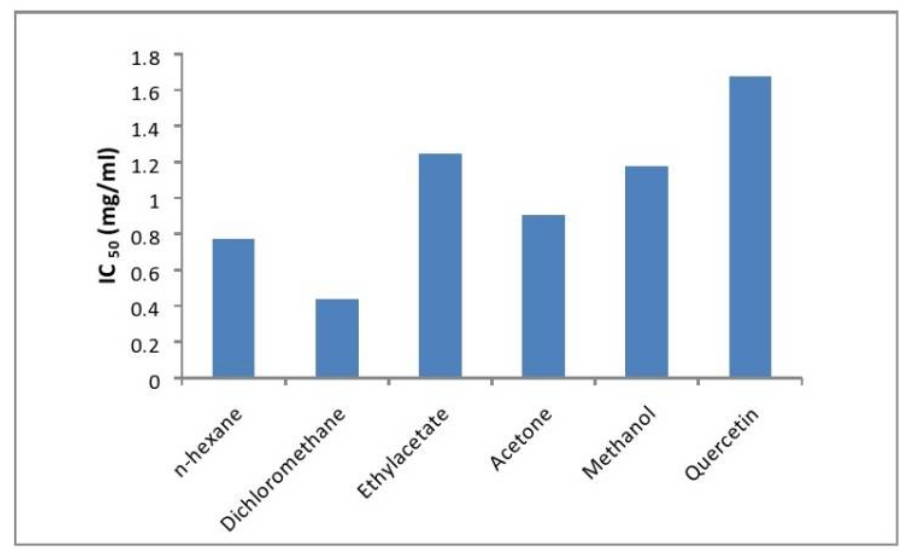

Fig. 7. $\mathrm{IC}_{50}$ values of Rubroboletus himalayensis and Quercetin for DPPH assay.

In our phylogenetic study based on the ITS dataset, reported species form distinct position within the clade of $R$. dupainii, $R$. lupinus, $R$. latisporus, $R$. esculentus and $R$. rhodoxanthus. These species don't have prominent reticulated stipe and can be easily separated from $R$. haematinus, $R$. legaliae, $R$. pulcherrimus, $R$. pulchrotinctus, $R$. rubrosanguineus, $R$. satanas and $R$. sinicus which have obvious reticula on the stipe (Both, 1993, 2009; Sarwar and Khalid, 2013; Sutara et al., 2009; Zhao et al., 2014).

Morphologically, more closely related species is $R$. dupainii due to bright red pileus and hymenophore as well as pale yellow context. However, stipe of $R$. himalayensis is club to irregular shaped with dots only toward apex as compared to equal stipe of $R$. dupainii. Another difference is that $R$. himalayensis is found associated with conifers while $R$. dupainii was found associated with oaks. Another related species is $R$. latisporus which can be distinguished from $R$. himalayensis due to its orange-red to yellow hymenophore when mature, while that of $R$. himalayensis is blood red to dark red as well as context whitish to greyish in former. $R$. lupinus can be differentiated by its pale pink to reddish pink pileal surface. $R$. rhodoxanthus can be easily differentiated due to no colour change of its stipe when injured. $R$. esculentus has yellow to bright yellow context while newly reported species has creamish context (Zhao et al., 2014; Zhao and Shao, 2017).

Mycochemical analysis of this newly described species was also done. Extraction yield in different solvents indicated highest yield in methanol and lowest in ethyl acetate and acetone. Extract yield depends on numerous elements such as the solvent used, polarity of the solvent and mushroom compounds (Tibuhwa, 2012). Other factors such as $\mathrm{pH}$, length of extraction time, temperature and the chemical composition of the mushroom can likewise incredibly influence the yield obtained (Awala and Oyetayo, 2015). The qualitative analysis revealed that proteins, triterpenoids, tannins, quinones and phenolics were present in mushroom while alkaloids, carbohydrates, steroids, saponins, flavonoids, anthocyanins were absent (Awala and Oyetayo, 2015). Quantitative analysis for estimation of total phenolic, flavonoid and tannin content was also carried out using spectrophotometric, n-hexane, dichloromethane, ethylacetate, acetone and methanol extracts of analyzed mushroom was subjected to DPPH radical scavenging assay at 
concentrations of $0.125,0.25,0.5$ and $1 \mathrm{mg} / \mathrm{ml}$ to find out antioxidant potential. Antioxidant activity at $1 \mathrm{mg} / \mathrm{ml}$ concentration (dichloromethane extract) was $98.14 \%$ while at $0.125 \mathrm{mg} / \mathrm{ml}$ concentrations (dichloromethane extract) it was $-34.43 \%$. Popescu et al. (2016) found that the antioxidant activity of Boletus edulis, Armillaria mellea and Macrolepiota procera demonstrated the additive content of active substances (polysaccharides, minerals) in overall antioxidant ability. The antioxidant properties of wild mushrooms were also abundantly studied by many researchers. The most common curative mushroom, for instance, is Ganoderma lucidum. Its antioxidizing activity is principally due to its terpenoids, phenolic and polysaccharide polypeptide contents (Reynante et al., 2014). Mycochemical screening and antioxidant activity of this new species was also done to highlight the importance of this species.

\section{Conflict of Interest}

This work is original and there is no conflict of interest.

\section{References}

Alessio, C.L. 1985. Boletus Dill. ex L. (sensu lato). Fungi Europaei. Vol. 2. Libreria editrice Biella Giovanna, Saronno.

Awala, S.I. and Oyetayo, O.V. 2015. Molecular identification and antimicrobial profile of Trametes species collected from the Teaching and Research Farm of the Federal University of Technology, Akure, Nigeria. Journal of Advances in Medical and Pharmaceutical Sources. 4(3): 1-14.

Bernas, E., Jaworska, G. and Lisiewska, Z. 2006. Edible mushrooms as a source of valuable nutritive constituents. Acta Scientiarum Polonorum. 5: 5-20.

Both, E.E. 1993. The Boletes of North America. Buffalo Museum of Science, New York. pp. 416.

Both, E.E. 2009. The second record of the European species, Boletus dupainii, in North America. Bul. Buffalo. Soc. Nat. Sci. 38: $1-4$.

Edgar, R.C. 2004. MUSCLE: multiple sequence alignment with high accuracy and high throughput. Nucleic. Acids. Res. 32(5): 1792-97.

Estadès, A. and Lannoy, G. 2004. Les bolets européens. Bulletin Mycologique et Botanique DauphinéSavoie. 44(3): 3-79.

Gardes, M. and Bruns, T.D. 1996. Community structure of ectomycorrhizal fungi in a Pinus muricata forest: Above- and below-ground views. Can. J. Bot. 74: 1572-1583.

Harborne, J.B. 1973. Phytochemical Methods. (UK, London: Chapman and Hall, Ltd.). pp. 49-188.

Hatano, T., Kagawa, H., Yasuhara, T. and Okuda, T. 1988. Two new flavonoids and other constituents in licore root: their relative astringency and radical scavenging affects. Chem. Pharm. Bull. 36: 1090-2097.

Jukes, T.H. and Cantor, C.R. 1969. Evolution of protein molecules. In: Munro HN, (ed), Mammalian protein metabolism. Academic Press, New York. pp. 21-132.

Lemieszek, M.K., Ribeiro, M., Alves, H.G., Marques, G., Nunes F.M. and Rzeski, W. 2016. Boletus edulis ribonucleic acid- a potent apoptosis inducer in human colon adenocarcinoma cells. Food. Funct. 7(7): 3163-3175.

Lucas, E.H., Ringler, R.L., Byerrum, R.U., Stevens, J.A., Clarke, D.A. and Stock, C.C. 1957. Tumor inhibitors in Boletus edulis and other Holobasidiomycetes. Antibiot Chemother. 7: 1-14.

Luo, A., Luo, A., Huang, J. and Fan, Y. 2012. Purification, characterization and antioxidant activities in vitro and in vivo of the polysaccharides from Boletus edulis Bull. Molecules. 17: 8079-90.

Muñoz, J.A. 2005. Boletus s.1. (excl. Xerocomus). Fungi Europaei 2. Edizioni Candusso, Alassio.

Naseer, A., Sarwar, S., Khalid, A.N., Healy, R. and Smith, M.E. 2019. Hortiboletus kohistanensis: a new species from temperate and subalpine oak forests of Pakistan. Phytotaxa. 388(3): 239-246.

Palacios, I., Lozano, M., Moro, C., D’Arrigo, M., Rostagno, A.M., Martínez, A.J., García-Lafuente, A., Guillamon, E. and Villares, A. 2011. Antioxidant properties of phenolic compounds occurring in edible mushrooms. Food. Chem. 128: 674-678. 
Parihar, S., Viranit, D.K., Pithawala, A.E., Shukla, D.M., Lahiri, K.S., Jam, K.N. and Modi, A.H. 2015. Phytochemical screening, total phenolic content, antibacterial and antioxidant activity of wild edible mushroom Pleurotus ostreatils. Int. Res. J. Pharm. 6(1): 65-69.

Pascua, S.M., Kalaw, P.S. and De Leon, M.A. 2016. Proximate composition, mycochemical analysis and antibacterial activity of Lentinus squarrosulus (Mont.) Singer. Adv. Environ. Biol. 10(3): 58-68.

Popescu, M.L., Costea, T., Nencu, I., Duţu, L.E. and Gîrd, C.E. 2016. Polyphenols contents and antioxidant activity of some Romanian wild edible mushrooms. Farmacia. 64(2): 231-236.

Ram, P.R. and Mehrotra, B.N. 1993. Compendium of Indian medicinal plants, (Drug Research Preparative: A CDRI Series), VOL. 2, Central Drug Research Institute, Lucknow and Publications and Information Directorate, New Delhi. 453 pp.

Reynante, G.B., Dulay, R.M.R., Bauto, J.J., Pascual, F., Baltazar, K., Bunag, H.W., Macatula, A., Nicolas, M.A., Torres, M.A.M., Nillosa, J.C., et al. 2014. Mycochemical profile of mycelia and fruiting body of Panaeolus cyanescens and its optimal submerged culture conditions for antioxidant properties. Int. J. Pure. App. Biosci. 2(6): 175-181.

Ribeiro, B., Rangel, J., Valentão, P., Baptista, P., Seabra, R.M. and Andrade, P.B. 2006. Contents of carboxylic acids and two phenolics and antioxidant activity of dried Portuguese wild edible mushrooms. J. Agr. Food. Chem. 54: 8530-8537.

Sanchez, C. 2010. Cultivation of Pleurotus ostreatus and other edible mushrooms. Appl. Microbiol. Biotechnol. 85(5): 1321-1337.

Sarwar, S. and Khalid, A.N. 2013. Addition to the Boletes: Boletus Pakistanicus sp. nov. from the Coniferous Forests of Pakistan. Int. J. Agric. Biol. 16(3): 663-667.

Sarwar, S. 2013. Boletes and their ectomycorrhizal morphotypes from some coniferous forests of Pakistan. $\mathrm{PhD}$ dissertation, Botany Department, University of the Punjab, Lahore.

Singer, R. and Kuthan, J. 1976. Notes on boletes. Česká Mykologie. 30: 143-155.

Šutara, J., Mikšík, M. and Janda, V. 2009. Hřibovité houby. Čeled' Boletaceae a rody Gyrodon, Gyroporus, Boletinus a Suillus. Praha: Academia.

Tamura, K., Peterson, D., Peterson, N., Stecher, G., Nei, M. and Kumar, S. 2011. MEGA5: Molecular evolutionary genetics analysis using maximum likelihood, evolutionary distance, and maximum parsimony methods. Mol. Biol. Evol. 28: 1731-1739.

Tibuhwa, D.D. 2012. Antiradical and antioxidant activities of methanolic extracts of indigenous termitarian mushroom from Tanzania. Food. Sci. Qual. Manag. 7: 13-23.

Vamanu, E. and Nita, S. 2013. Antioxidant capacity and the correlation with major phenolic compounds, anthocyanin, and tocopherol content in various extracts from the wild edible Boletus edulis mushroom. Biomed. Res. Int. Article ID313905. https://www.hindawi.com/journals/bmri/ 2013/ 313905/abs/

Wang, D., Sun, S.Q., Wu, W.Z., Yang, S.L. and Tan, J.M. 2014. Characterization of a water-soluble polysaccharide from Boletus edulis and its antitumor and immunomodulatory activities on renal cancer in mice. Carbohydr. Polym. 105(25): 127-34.

Werle, E., Schneider, C., Renner, M., Völker, M. and Fiehn, W. 1994. Convenient single-step, one tube purification of PCR products for direct sequencing. Nucleic Acids res. 22: 4354-4355.

White, T.J., Bruns, T.D., Lee, S. and Taylor, J. 1990. Amplification and direct sequencing of fungal ribosomal RNA genes for phylogenetics. PCR Protocol, a Guide to Methods and Applications. Academic Press, San Diego. pp. 315-322.

Zhao, K. and Shao, H.M. 2017. A new edible bolete, Rubroboletus esculentus, from southwestern China. Phytotaxa. 303(3): 243-52.

Zhao, K., Wu, G. and Yang, Z.L. 2014. A new genus, Rubroboletus, to accommodate Boletus sinicus and its allies. Phytotaxa. 188(2): 61-77.

(Manuscript received on 21 August, 2020; revised on 19 May, 2021) 